\title{
A Study on the Utilization Factors and Effects of Big Data in SMEs
}

\author{
Do-Hyung Yee*1, Yen-Yoo You ${ }^{2}$ \\ $*^{1}$ Doctoral Student, Dept. Of Knowledge Service \& Consulting, Hansung University, 02876, Seoul, Korea \\ ${ }^{2}$ Professor, Dept. of Smart Management Engineering, Hansung University, 02876, Seoul, Korea \\ andy@lon2seo.com*1, threey0818@hansung.ac.kr²
}

\begin{abstract}
Article History:Received:11 november 2020; Accepted: 27 December 2020; Published online: 05 April 2021
Abstract: Background/Objectives: The purpose of this study was to derive major utilization factors that can increase the practical data utilization ability of SMEs by utilizing big data, and examine the utilization methods and effects.

Methods/Statistical analysis: This study derives the utilization factors and effects of organizational, technical, environmental, and policy aspects so that SMEs can increase their data utilization capabilities. The target was for SME managers or members. Frequency analysis was conducted to understand the distribution by demographic characteristics, and the relationship between factors and effects was measured through factor analysis, correlation analysis, and regression analysis for the measured variables.
\end{abstract}

Findings: Perform regression to analyze the impact, utilization, and impact of independent variables on technology, organizational gender, environment, and policy performance as dependent variables

Durbin-Watson's index was below 2.1 and self-relevant and had the power to explain the impact of independent variables such as organizational gender, technology, environment, and policy on utilization. In terms of application, it was found that the use of big data had an effect on education and human resource development rather than the perception of managers and members. Therefore, it was found that education related to big data and in-house experts were recognized as necessary. On the effective side, it was found that the perception of managers and employees influenced. It was found that corporate members thought that when promoting big data, promoting it with the strong will of the manager is an effective aspect for using big data.

Improvements/Applications: If you possess the infrastructure and knowledge in the company, and improve the system with the support of members, it will be an opportunity to increase the utilization of it

Keywords: AI, Big Data, Digital Marketing, Small and Medium Business, Data policy

Introduction

Artificial Intelligence, Information and Communications Technologies, Internet of The world is changing due to the 4th industrial revolution such as Things, Smart Factory, and Blockchain. Big data is at the center of this change. With this data, from large companies to small and medium-sized enterprises and single-person companies, it occupies an important position in the corporate business from data processing, data distribution, and data utilization. As the importance of big data analysis in companies increases, there is an increasing desire to collect and analyze from structured data to unstructured data. In fact, data collected from various sensors installed on production lines in the manufacturing field are linked to IoT technology and transformed into IoT data. It is used for predictive maintenance of facilities and analysis of defect rates. In addition, various activities such as analysis of consumer propensity and management of buildings and bridges are carried out using unstructured data.Appropriate investment in big data will lead to a wave of fundamental technological advances that enable analysis platforms and big data management, products and systems to be implemented in the next generation [1]. The representative field that is currently using big data most actively is digital marketing. Digital marketing is evolving in the direction of further enhancing targeting accuracy, in line with the information distribution rule in the digital age of providing customized content to the desired person at the right time. The use of such big data reduces corporate risk and contributes a lot to corporate marketing and manufacturing. There were a total of 6.3 million SMEs in Korea as of the end of 2017, and 99.9\% of all companies were found to fall into this. Office workers working in SMEs accounted for 82.9\% (15.99 million) of domestic corporate employees [2]. Because SMEs are small and flexible, they can cope with changing environments faster than large companies. However, there are many difficulties related to the use of big data as seen in domestic statistics. Currently, it is large companies that can actively respond to the big data environment. Collecting necessary analysis data to utilize big data, fostering and hiring professional manpower, building analysis infrastructure, etc. It costs money. Most of the domestic SMEs are trying to solve this problem by themselves, and the government is implementing various policies to increase SMEs' ability to use big data. There are 'National Agency Strategic Industry Job Training, 'Data Store, and Small and Medium Business Big Data Utilization Support Project, and big data solutions in cloud environments for small and medium-sized companies are also increasing. In addition, the big data voucher business, which has been implemented since 2019, is a business that recruits data sales providers and data processing companies, and connects data use demanding companies, leading the vitalization of the data market of SMEs. Businesses use big data To leverage advanced analytics and improve performance, companies must be able to identify, combine, and

*Corresponding author: Do-Hyung Yee

Doctoral Student, Dept. Of Knowledge Service \& Consulting,

Hansung University, 02876, Seoul, Korea . andy@lon2seo.com 
manage multiple data sources, the ability to build advanced analytics models to predict and optimize results, and the power to transform organizations to make better decisions. Must have[3] Therefore, it is necessary to have an infrastructure that can utilize data analysis throughout the enterprise among the useful factors in utilizing big data for companies[4]. The purpose of this study is to examine the market environment, use and effect of big data of SMEs. Report In the current environment of COVID-19, the global economic downturn. We present the factors and effects of big data.

\section{Theory and formula}

American companies conducted research on improving corporate competitiveness through IT investment. The study found that U.S. companies, which had been encroached by Japanese and European companies, improved productivity and improved corporate performance through IT investment and IT utilization [5]. As factors that influence the organization's introduction of information technology, there are three perspectives: technological, organizational, and environmental aspects. Among them, environmental factors refer to factors that a company performs and affects the company both inside and outside the industry. In general, environmental factors include the industry, competitors, suppliers, public and government agencies, etc. currently doing business [6]. In a joint study with IBM, more than 3,000 corporate executives from more than hundred pieces countries around the world. The study of how organizations use data management and analysis for decision-making and execution with insight was conducted on gin, managers and analysts, and the survey found that top-performance organizations had five times more analytical capabilities than those that did not [7]. As data emerges as a key driver of the competitiveness of products and services, well-produced, accumulated and utilized data is becoming an important indicator of the value and competitiveness of countries and businesses and serves as the core of competition. Recognizing the importance of big data, Korean conglomerates are trying to take new approaches in various areas such as product and service planning, production and operation management, Marketing and public relations by establishing strategies for utilizing data. Under these circumstances, small and medium-sized companies are trying to create new business opportunities by utilizing big data, but they are hesitant to introduce big data technologies due to lack of professional manpower and cost burdens. Small and medium-sized companies need to actively review big data utilization as the biggest reason for the poor utilization of big data is the lack of awareness (80.6\%, multiple responses) of big data, and the results of the big data show that the companies have been able to expand the creation of new products and services, improve efficiency, satisfy customers, and reduce costs. We need to use big data to solve various problems that small and medium-sized enterprises have and allow them to experience success stories. Companies should be able to make improved decisions based on knowledge derived from measuring and analyzing their business using big data and transform them into performance [8]. There are four areas where small and medium-sized businesses can utilize big data[9] First, internal decision making and efficiency improvement. Business performance can be enhanced by monitoring the management environment in real time, such as production process and logistics situation, and establishing a system that enables immediate response. Although it was a form of response to management and manufacturing processes in the past, it is possible to proactively manage various risk factors that may occur in the future by utilizing big data. As largescale information is collected and analyzed, risk management such as anomaly prediction and warning of highrisk situations can be performed. Second, high value-added products through development of new products and services In the process of planning and designing new products, information and principles necessary for all key decisions can be obtained as a result of big data analysis. A solution can be derived by systematic analysis. Third, customer identification and marketing differentiation. Real-time marketable market and consumer information enable efficient target marketing and discover new patterns in consumer daily behavior data to derive needs and marketing methods that customers do not recognize. This allows customers to use brand positioning strategies by selecting customized products for each customer.

\section{Experimental setup}

Research on big data is being approached from many aspects, but there are few cases of companies that have benefited from the results of big data. However, it is expected that companies' interest in big data will continue to increase, so it is important to study to identify and present the main factors to be expected using big data. This paper aims to increase the practical data utilization ability of SMEs. The main factors that can be used will be identified and examined, and the application methods and effects based on these factors will be explored. The research model is as follows. 


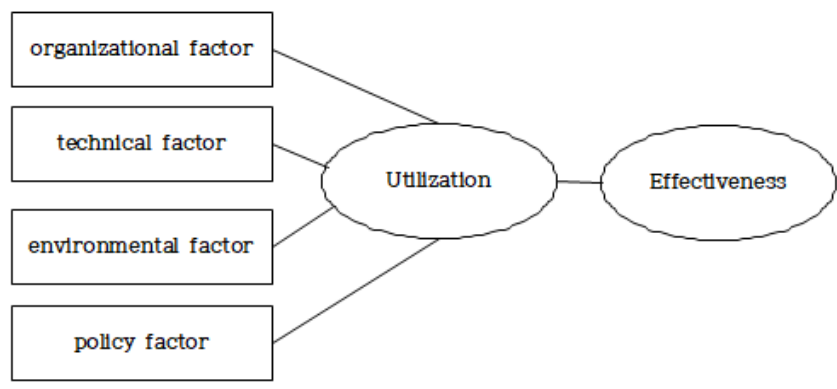

Figure 1. Leverage Big Data-Effect Model

In this study, the recognition of managers and members, education, and human resources development were established as organizational recognition factors. As a technical recognition factor, the system was introduced and the type of tester was set. The investment environment and infrastructure construction were established as environmental factors. In terms of policy recognition factors, information security and government policy were set. The following hypothesis was established by looking at the influence of each factor on utilization and effectiveness:

1) Hypothesis on the relationship between utilization and effect in terms of organization

2) Hypothesis on the relationship between utilization and effect in terms of technology

3) The hypothesis of utilization and effectiveness in the environmental aspect.

4) The hypothesis of the relationship between utilization and effectiveness in terms of policy.

5) The Relationship between the Utilization and Effect of Big Data

It is suggesting four principles for utilizing big data. First, the use of big data is a kind of corporate culture, and in order to utilize big data within an organization, a consensus on the need and value must be formed. Second, we will realize information management and secure capabilities by securing and deploying appropriate people. Third, we should focus on data utilization first by selecting appropriate information management tasks to accumulate execution experience, and promote the knowledge produced as the biggest opportunity and use cases. Fourth, the latest techniques and technologies are important, but it is also the beginning of big data analysis [10]. Looking at the trends in effect, it is expected to be most directly and indirectly affected by the research on the use and use of big data in the marketing sector and in the production sector. These include reducing business costs through predicting market fluctuations and consumer behavior, improving product efficiency, and improving productivity through differentiation. Furthermore, in order for a company to achieve its social and economic objectives and secure a competitive advantage, which is the legitimacy of its activities, it must be determined in order to receive decisions about the management system, organization, audit system, and decision.

\section{Result discussions}

In this research analysis, a survey was conducted to derive utilization factors from organizational, technical, environmental, and policy aspects that can enhance the practical data utilization capabilities of small and medium enterprises and to examine utilization methods and effects based on utilization factors. The targets were small business managers or members. Frequency analysis was conducted to identify distribution by demographic characteristics, and the survey was conducted on age, gender, industry, position, work experience, length of service, experience working in big data departments, and big data education used for Reliability analysis and feasibility analysis were performed to measure the accuracy, precision, and reliability of internal consistency of measurement tools between measurement questions. Factor analysis was performed on the measurement variables. The purpose of the factorial analysis is to reduce the data and conduct an exploratory factorial analysis of independent variables for validity verification. In order to verify the validity, Kaiser-MeyerOlkin sample adequacy of standard formation is superior to 0.9 , and data values of 0.786 validity are reasonably met if there are 0.8 0.9 and 0.7 0.8. The factors that are grouped into four factors are as shown below, the factors are as follows:

Table 1: Factor analysis -rotated component matrix

\begin{tabular}{|c|c|c|c|c|c|}
\hline \multicolumn{2}{|c|}{ Factor analysis } & \multicolumn{4}{|c|}{ factors } \\
\cline { 3 - 5 } & 1 & 2 & 3 & 4 \\
\hline $\begin{array}{l}\text { Environ } \\
\text {-mental }\end{array}$ & $\begin{array}{c}\text { Investment Environment- } \\
\text { Utilization }\end{array}$ & 0.824 & 0.122 & -0.02 & 0.3 \\
\hline
\end{tabular}




\begin{tabular}{|c|c|c|c|c|c|}
\hline \multirow[t]{3}{*}{ factors } & $\begin{array}{l}\text { Investment environment- } \\
\text { effect }\end{array}$ & 0.73 & 0.218 & 0.449 & -0.08 \\
\hline & Infrastructure-Effect & 0.698 & 0.196 & 0.171 & 0.153 \\
\hline & Infrastructure-Utilization & 0.679 & 0.393 & 0.117 & 0.124 \\
\hline \multirow{4}{*}{ Technical factors } & System introduction-effect & 0.58 & 0.475 & 0.009 & 0.302 \\
\hline & Data type-use & 0.157 & 0.782 & 0.086 & 0.129 \\
\hline & Data Type-Effect & 0.372 & 0.672 & 0.24 & 0.107 \\
\hline & $\begin{array}{c}\text { System introduction- } \\
\text { utilization }\end{array}$ & 0.554 & 0.654 & 0.208 & 0.095 \\
\hline \multirow{4}{*}{ Policy factors } & Government policy-effect & 0.075 & 0.133 & 0.877 & 0.069 \\
\hline & $\begin{array}{c}\text { Government Policy- } \\
\text { Utilization }\end{array}$ & 0.131 & 0.291 & 0.862 & 0.056 \\
\hline & $\begin{array}{c}\text { Corporate information } \\
\text { protection-effect }\end{array}$ & 0.394 & -0.213 & 0.565 & 0.535 \\
\hline & $\begin{array}{l}\text { Corporate information } \\
\text { protection-utilization }\end{array}$ & 0.471 & 0.179 & 0.511 & 0.269 \\
\hline \multirow{4}{*}{$\begin{array}{l}\text { Organizational } \\
\text { factors }\end{array}$} & Member recognition-effect & 0.154 & 0.423 & -0.168 & 0.743 \\
\hline & $\begin{array}{c}\text { Member recognition- } \\
\text { utilization }\end{array}$ & 0.157 & 0.258 & 0.208 & 0.705 \\
\hline & $\begin{array}{c}\text { Human Resource } \\
\text { Development-Utilization }\end{array}$ & 0.083 & 0.201 & 0.44 & 0.67 \\
\hline & $\begin{array}{c}\text { Human resource } \\
\text { development-effect }\end{array}$ & 0.39 & 0.162 & 0.166 & 0.506 \\
\hline
\end{tabular}

Correlation number was obtained through correlation analysis. Before the regression analysis, the correlation between independent variables and the relationship between independent variables and dependent variables was reviewed and the correlation between independent variables and dependent variables was performed by injecting both independent variables and dependent variables to prepare for multicollinearity. Correlation refers to the relationship between variables. The degree of correlation is shown between 0 and \pm 1 . The closer to \pm 1 , the higher the correlation, and the closer to zero, the lower the correlation.

Table 2: Correlation analysis. - Correlation number

\begin{tabular}{|c|c|c|c|c|c|}
\hline \multicolumn{2}{|r|}{ factors } & $\begin{array}{c}\text { Organiza } \\
\text {-tional }\end{array}$ & Technical & $\begin{array}{c}\text { Environ } \\
\text { mental }\end{array}$ & Policy \\
\hline \multirow{3}{*}{$\begin{array}{l}\text { Organiza } \\
\text {-tional }\end{array}$} & Pearson correlation coefficient & 1 & $.654^{* * *}$ & $.556^{* * *}$ & $.505^{* *}$ \\
\hline & Significance level (both sides) & & .000 & .000 & .000 \\
\hline & $\mathrm{N}$ & 106 & 106 & 106 & 106 \\
\hline \multirow{3}{*}{$\begin{array}{l}\text { Technical } \\
\text { factors }\end{array}$} & Pearson correlation coefficient & $.654 * *$ & 1 & $.720^{* * *}$ & $.455^{* *}$ \\
\hline & Significance level (both sides) & .000 & & .000 & .000 \\
\hline & $\mathrm{N}$ & 106 & 106 & 106 & 106 \\
\hline \multirow{3}{*}{$\begin{array}{c}\text { Environ } \\
\text { mental }\end{array}$} & Pearson correlation coefficient & $.556^{* *}$ & $.720^{* *}$ & 1 & $.548^{* *}$ \\
\hline & $\begin{array}{l}* * \text { The correlation is significant at the } \\
0.01 \text { level (both sides). }\end{array}$ & .000 & .000 & & .000 \\
\hline & $\mathrm{N}$ & 106 & 106 & 106 & 106 \\
\hline \multirow{3}{*}{ Policy } & Pearson correlation coefficient & $.505 * *$ & $.455^{* * *}$ & $.548^{* * *}$ & 1 \\
\hline & Significance level (both sides) & .000 & .000 & .000 & \\
\hline & $\mathrm{N}$ & 106 & 106 & 106 & 106 \\
\hline
\end{tabular}


In the final step, the relationship with the factors was measured through a regression analysis. It is a representation of the results of correlation analysis between variables. The correlation between the factors shows that they have the following characteristics: The correlation between organization and organization is one. The correlation coefficient of the magnetic variable is 1 . Organizational performance is technical.654 correlates environmental performance with .556 policy performance. It showed a correlation of 505. Overall, environmental and technological. It showed the highest correlation at 720.

Table 3: Regression analysis-Model summary

\begin{tabular}{|c|c|c|c|c|c|}
\hline Factor & $\mathrm{R}$ & R Square & $\begin{array}{c}\text { adjusted R } \\
\text { square }\end{array}$ & $\begin{array}{c}\text { Standard } \\
\text { Estimate Error }\end{array}$ & Durbin-Watson \\
\hline Utilization & $.670 \mathrm{a}$ & .449 & .403 & .40190 & 2.137 \\
\hline Effect & $.716 \mathrm{a}$ & .513 & .473 & .38704 & 2.112 \\
\hline
\end{tabular}

A multi-recovery analysis was conducted to identify the organizational, technological, environmental, policy and dependent variables in the utilization factors. If the Durbin-Watson index is close to zero, it's positive autocorrelation. If it's close to four, it's negative autocorrelation. It's 2.137, and the adjusted R square is 0.4019 , which is about $40.1 \%$. They have the ability to explain the impact of organizational, technical, environmental and policy variables on utilization. For effective factors, multiple regression analyses were conducted to identify the organizational, technical, environmental, policy and the effect of dependent variables. The Durbin-Watson index is not self-contained at 2.112, and the adjusted $\mathrm{R}$ square value is 0.473 , giving an explanation of the effects of organizational, technical, environmental and policyability, which are independent variables of about $47.3 \%$

\section{Conclusions}

In the paper, the organization presented by Tornatzky \& Fleischerk tried to derive and report key factors from organizational, technical, environmental and policy aspects, including three perspectives on technical, organizational and environmental aspects, as factors affecting the introduction of information technology, and to seek methods and effects of utilization. Based on the preceding study, factors were extracted from each side, hypothesized, and analyzed using independent and dependent variables. The findings were derived as follows: In terms of utilization, education and human resources development affect the utilization of big data rather than the perception of managers and members. It seems that education and in-house experts are needed to utilize big data, and $24.5 \%$ of working experience in big data departments in frequency analysis, while $66 \%$ of in-house education related to big data is found to recognize that big data-related education and in-house experts are needed to utilize big data. On the effective side, it has been shown that awareness among managers and members has an impact. Although 17 percent of the respondents were managers in frequency analysis, the company members thought that it was an effective aspect of utilizing big data to push ahead with the strong will of managers when promoting big data. This study leaves the following implications. First, depending on the rapidly changing big data related hardware and software. The internal human resources and knowledge of the company's infrastructure and environment. If you have it, you can use and benefit from big data. Second, if the big data system is introduced or improved with the active support and will of its members, and it takes root as a corporate culture, it will be an opportunity to use big data utilization. Third, through macro support of the government's policies related to big data, it should be steadily promoted to have the effect of revitalizing the reinforced cloud big data, creating a market environment that activates the data voucher system, and activating transactions through the MyG system.

\section{Acknowledgements}

This research was financially supported by Hansung University

\section{References}

1. Agrawal, D., Das, S., \& El Abbadi, A. (2011, March). Big data and cloud computing: current state a nd future opportunities. In Proceedings of the 14th international conference on extending database tec hnology (pp. 530-533)

2. Doh, S., \& Kim, B. (2014). Government support for SME innovations in the regional industries: The case of government financial support program in South Korea. Research Policy, 43(9), 1557-1569.

3. Barton, D., \& Court, D. (2012). Making advanced analytics work for you. Harvard business review, 9 $0(10), 78-83$.

4. Alharthi, A., Krotov, V., \& Bowman, M. (2017). Addressing barriers to big data. Business Horizons, 60(3), 285-292.

5. Quinn, J. B., \& Baily, M. N. (1994). Information technology: increasing productivity in services. Aca 
demy of Management Perspectives, 8(3), 28-48.

6. Tornatzky, L. G., Fleischer, M., \& Chakrabarti, A. K. (1990). Processes of technological innovation. Lexington books.

7. LaValle, S., Lesser, E., Shockley, R., Hopkins, M. S., \& Kruschwitz, N. (2011). Big data, analytics a nd the path from insights to value. MIT sloan management review, 52(2), 21-32.

8. McAfee, A., Brynjolfsson, E., Davenport, T. H., Patil, D. J., \& Barton, D. (2012).

9. Big data: the management revolution. Harvard business review, 90(10), 60-68.

10. Lee, M. (2018). Analysis of the Impacts of South Korea's Political Relations on its Bilateral Trade: F ocus on South Korea's Political and Trade Relations with China, Japan, Russia, and North Korea.

11. Go Jun-cheol, Hae-wook Lee, Ji-yoon Ji-yoon, and Kyung-sik Kang. (2012). Big data's new customer value and response strategy for business creation. Journal of the Korean Safety Management Science, 14 (4), 229-238. 